\title{
STUDY ON THE INCIDENCE OF TESTICULAR AND EPIDIDYMAL APPENDAGES IN PATIENTS WITH CRYPTORCHIDISM
}

\author{
LUCIANO A. FAVORITO, ANDRÉ G.L. CAVALCANTE; MARCIO A. BABINSKI \\ Urogenital Research Unit, State University of Rio de Janeiro, UERJ, and Souza Aguiar Municipal Hospital, \\ Rio de Janeiro, RJ, Brazil
}

\begin{abstract}
Objective: To study the incidence of testicular and epididymal appendages in patients with cryptorchidism.

Materials and Methods: We studied 65 patients with cryptorchidism, totalizing 83 testes and 40 patients who had prostate adenocarcinoma and hydrocele (control group), totalizing 55 testes. The following situations were analyzed: I) absence of testicular and epididymal appendages, II) presence of testicular appendage only, III) presence of epididymal appendage, IV) presence of testicular and epididymal appendage, $\mathrm{V}$ ) presence of 2 epididymal appendages and 1 testicular appendage and VI) presence of paradidymis or vas aberrans of Haller.

Results: In patients with cryptorchidism we found testicular appendages in 23 cases (41.8\%), epididymal appendages in $9(16.3 \%)$, testicular and epididymal appendage in $8(14.5 \%), 2$ epididymal appendages and 1 testicular in $1(1.8 \%)$ and absence of appendages in $14(25.4 \%)$. In the control group, we found testicular appendages in 29 (34.9\%), epididymal appendages in 19 (22.8\%), testicular and epididymal appendage in $7(8.4 \%)$, and absence of appendages in $28(33.7 \%)$, we did not find 2 epididymal appendages in this group, and none of the patients in the 2 groups presented paradidymis or vas aberrans of Haller.

Conclusion: The occurrence of testicular and epididymal appendages is quite variable. There was no statistically significant difference in the incidence and distribution of the testicular and epididymal appendages between patients with cryptorchidism and those from the control group.
\end{abstract}

Key words: testis; epididymis; cryptorchidism

Int Braz J Urol. 2004; 30: 49-52

\section{INTRODUCTION}

Testicular and epididymal appendages were once considered anatomic anomalies (1), however some studies report that these structures are present in the majority of normal individuals (2). Such appendages, when they are too long or pedunculated, can twist around their own axis, causing very painful symptoms, simulating torsion of the spermatic cord $(3,4)$. There are also reports on tumors originated from these structures (5).
The testicular appendage derives from the upper portion of the paramesonephric duct, and is also known as sessile hydatid of Morgagni (6). The portion of the mesonephric duct that is cranial to the testis can form the pedunculated hydatid of Morgagni, currently known as epididymal appendage.

Other vestigial structures derived from this portion of the mesonephric duct are the "Haller's organs", located in the fissure between the testis and the epididymis, consisting of a group of superior and inferior aberrant vessels, and the "Giraldes' organ", 
also called paradidymis or innominate body, located in the distal portion of the spermatic cord $(2,6)$ (Figure 1).

There are several studies analyzing the macro and microscopic structure of the testicular and epididymal appendages in the literature $(2,7)$. The study of the incidence of such structures in patients with cryptorchidism and the comparison of these findings with individuals without anomalies in testicular position are rare in the literature.

The objective of this work is to study the incidence of the testicular and epididymal appendages in patients with cryptorchidism, using patients who underwent subcapsular orchiectomy or surgical treatment of hydrocele as a control group.

\section{MATERIALS AND METHODS}

In the period from March 2001 to January 2004, we studied 65 patients having cryptorchidism, with ages ranging from 1 to 18 years who underwent orchiopexy, totalizing 83 testes, and 40 patients having prostate adenocarcinoma and hydrocele (control group), with ages ranging from 5 to 82 years, submitted to orchiectomy or surgical treatment of hydrocele, totalizing 55 testes. All patients with cryptorchidism had their testes located in the inguinal canal and all patients from the control group had their testes located in the scrotum.

We analyzed the following situations in the 2 groups, during the surgeries: I) absence of testicular and epididymal appendages, II) presence of testicular appendage only, III) presence of epididymal appendage, IV) presence of testicular and epididymal appendage, $\mathrm{V}$ ) presence of 2 epididymal appendages and 1 testicular appendage, and VI) presence of paradidymis or vas aberrans of Haller.

The qui-square statistical test was used for comparison between the 2 populations (8).

\section{RESULTS}

The results of incidence of testicular and epididymal appendages in patients with cryptorchidism and in the control group, according to the 6 proposed situations, are demonstrated in the Table 1.
In patients with cryptorchidism we found testicular appendages in 23 cases (41.8\%), epididymal appendage in $9(16.3 \%)$, testicular and epididymal appendage in 8 (14.5\%), 2 epididymal appendages and 1 testicular in $1(1.8 \%)$, and absence of append-

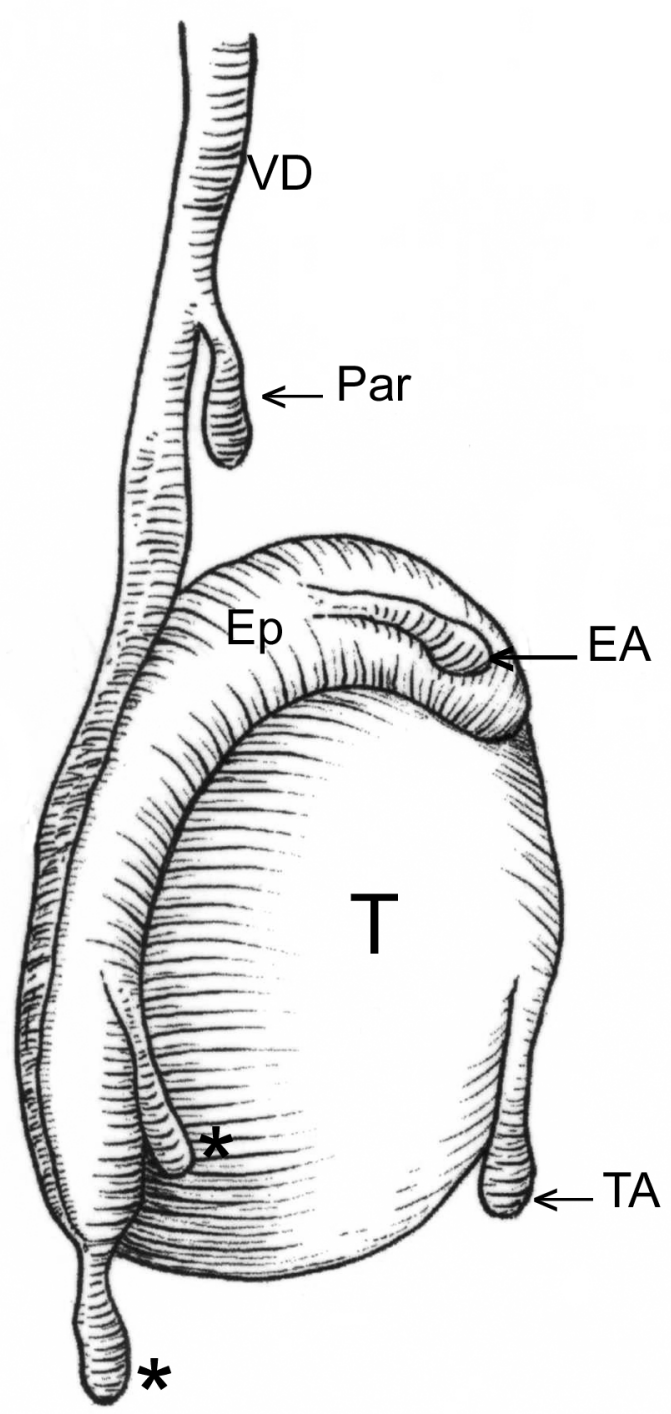

Figure 1 - The scheme evidences the most frequent location of testicular and epididymal appendages. TA = testicular appendage, EA = epididymal appendage, Par = paradidymis; asterisks = superior and inferior vas aberrans of Haller, $T=$ testis, Ep = epididymis, $V D=$ vas deferens. (Illustration based on Rolnick $D$, Kawanoue S, Szanto P, Bush IM: Anatomical incidence of testicular appendages. J Urol. 1968; 100: 755-6). 
Table 1 - Incidence of testicular and epididymal appendages in patients with cryptorchidism and in patients who underwent orchiectomy or surgical repair of hydrocele, according to the 6 groups studied: I) absence of testicular and epididymal appendages, II) presence of testicular appendage only, III) presence of epididymal appendage, IV) presence of testicular and epididymal appendage, V) presence of 2 epididymal appendages and 1 testicular appendage, and VI) presence of paradidymis or vas aberrans of Haller.

\begin{tabular}{lll}
\hline Groups & Cryptorchidism & Control \\
\hline I & $14(25.4 \%)$ & $28(33.7 \%)$ \\
II & $23(41.8 \%)$ & $29(34.9 \%)$ \\
III & $9(16.3 \%)$ & $19(22.8 \%)$ \\
IV & $8(14.5 \%)$ & $7(8.4 \%)$ \\
V & $1(1.8 \%)$ & 0 \\
VI & 0 & 0 \\
Total & 83 & 55 \\
\hline
\end{tabular}

ages in $14(25.4 \%)$ cases. In the control group, we found testicular appendages in 29 (34.9\%), epididymal appendages in 19 (22.8\%), testicular and epididymal appendage in 7 (8.4\%), and absence of appendages in $28(33.7 \%)$ cases. We did not find 2 epididymal appendages and 1 testicular in any case in the control group. Paradidymis and vas aberrans of Haller were not found in any patient from either group

There was no statistically significant difference concerning the incidence and distribution of the testicular and epididymal appendages in the groups studied.

\section{DISCUSSION}

Cryptorchidism is one of the most common congenital pathologies in males, with an incidence of 2 to $5 \%$ in full-term births, which can reach $30 \%$ in premature births (9-11).
A number of anomalies are associated with cryptorchidism, however the epididymal anomalies and inguinal hernia are among the most frequent ones (1113). The epididymal anomalies are associated with cryptorchidism, with an incidence that ranges from 36 to $79 \%(14,15)$. The incidence of testicular and epididymal appendages is seldom reported in patients with cryptorchidism.

The knowledge of the presence, shape and location of the testicular and epididymal appendages is important, due to the possibility of torsion of such structures, association with anatomical anomalies, and the possibility of occurrence of tumors in theses structures $(2,5,12)$.

We found the presence of testicular appendage in more than $55 \%$ of patients with cryptorchidism and in $43 \%$ of patients from the control group. Rolnick et al. (2) in 100 necropsies found the testicular appendage in $92 \%$ of cases. Sundarasivarao (16) found testicular appendages in $80 \%$ of his sample.

In our sample, we detected epididymal appendages in $32 \%$ of patients with cryptorchidism and in $31 \%$ in the control group. Rolnick et al. (2) found this appendage in $34 \%$ of their casuistry, and Sundarasivarao (16) in 23\%. The presence of multiple testicular and epididymal appendages is rare $(2,7,16)$, a fact confirmed by our findings, where this anomaly was observed in only 1 case.

The occurrence of testicular and epididymal appendages is quite variable. We found no statistically significant difference in the incidence and distribution of the testicular and epididymal appendages between patients with cryptorchidism and those from the control group.

Support by grants from the Rio de Janeiro Foundation for Research Support (FAPERJ) and National Council for Scientific and Technological Development (CNPQ).

\section{REFERENCES}

1. Johansen TEB: Anatomy of the testis and epididymis in cryptorchidism. Andrologia. 1987; 19: 565-9. 
2. Rolnick D, Kawanoue S, Szanto P, Bush IM: Anatomical incidence of testicular appendages. J Urol. 1968; 100: 755-6.

3. Vermeulen CW, Hagerty CS: Torsion of the appendix testis (hydatid of Morgagni): report of two cases with a study of the microscopic anatomy. J Urol. 1945; 54: 459-65.

4. Krukowsky ZH, Auld CD: Torsion of the appendix epididymis in a maldescendent testis. Br J Urol. 1983; 55: 244-5.

5. Kernohan NM, Coutts AG, Best PV: Cystoadenocarcinoma of appendix testis. Histopathology. 1990, 17: 147-54.

6. Noske HD, Kraus SW, Altinkilic BM, Weidner W: Historical milestones regarding torsion of the scrotal organs. J Urol. 1998; 159: 13-16.

7. Sahni D, Jit I, Joshi K, Sanjeev: Incidence and structure of the appendices of the testis and epididymis. J Anat. 1996; 189: 3418.

8. Sokol RR, Rohlf FJ: Biometry, 3rd ed. New York, Freeman WH, 1995.

9. Cendron M, Huff DS, Keating MA, Snyder, III HM, Duckett JW: Anatomical, morphological and volumetric analysis: a review of 759 cases of testicular maldescent. J Urol. 1993; 149: 570-3.
10. Kogan S, Hadziselimovic F, Howards SS, Snyder III HM, Huff D: Pediatric Andrology, in Gillenwater JY, Grayhack JT, Howards SS Snyder III HM (eds): Adult and Pediatric Urology. St Louis, Mosby, 1996, 3rd ed, vol 3, pp 2623-2674.

11. Gill B, Kogan S: Cryptorchidism. Current concepts. Pediatr Clin North Am. 1997; 44: 1211-27.

12. Scorer CG, Farrington GH: Congenital Deformities of the Testis and Epididymis. London, Butter Worths e Co, 1971.

13. Marshall FF: Anomalies associated with cryptorchidism. Urol Clin North Amer. 1982; 9: 339-47.

14. Mollaeian M, Mehrabi V, Elahi B: Significance of epididymal and ductal anomalies associated with undescended testis: study in 652 cases. Urology. 1994; 43: 857-60.

15. Barthold JS, Redman JR: Association of epididymal anomalies with patent processus vaginalis in hernia, hydrocele and cryptorchidism. J Urol. 1996; 156: 20546.

16. Sundarasivarao D: The Müllerian vestiges and benign epithelial tumours of the epididimys. J Pathol Bacteriol. 1953, 66: 417-32.
Received: December 20, 2003 Accepted: January 17, 2004

\author{
Correspondence address: \\ Dr. Luciano A. Favorito \\ Urogenital Research Unit \\ Av. 28 de Setembro, 87, fundos, térreo \\ Rio de Janeiro, RJ, 20562-030, Brazil \\ Fax: + $55212587-6121$ \\ E-mail: favorito@uerj.br
}

